\title{
Formação de professores em uma perspectiva democrática: Encontros sobre o Poder Escolar
}

\section{Teacher training in a democratic perspective: Meeting about School Power}

\section{Formación de profesores desde una perspectiva democrática: Encuentros sobre el Poder Escolar}

\author{
Lígia Cardoso Carlos' \\ Universidade Federal de Pelotas (UFPel), Professora Associada da Faculdade de Educação e \\ do Programa de Pós-Graduação em Geografia \\ Dirlei de Azambuja Pereira² \\ Universidade Federal de Pelotas (UFPel), Professor Adjunto da Faculdade de Educação
}

Resumo: No presente artigo tem-se como propósito apresentar e discutir a respeito de um projeto de formação continuada de professores da educação básica que ocorre na Cidade de Pelotas, RS, Brasil, desde 2001 chamado Encontros sobre o Poder Escolar. Tomamos como referência nossa experiência de participação em diferentes etapas da organização e do desenvolvimento do Projeto e uma entrevista com a primeira coordenadora. Entendemos que dar visibilidade a essa ação de formação potencializa a ideia de aproximação e diálogo entre os saberes acadêmicos e os saberes construídos nos cotidianos da docência na escola, engendrando e fortalecendo processos de autonomia e vivência democrática.

Palavras-chave: Formação continuada. Democracia escolar. Educação básica.

Abstract: The purpose of this article is to present and discuss a continuing education project of primary school teachers in the city of Pelotas, RS, since 2001 called Meeting about School Power. We take as reference our experience of participating in different stages of the organization and development of the project and an interview with the first coordinator. We understand that giving visibility to this training action enhances the idea of

Doutora em Educação pela Universidade do Vale do Rio dos Sinos; Mestre em Educação pela Universidade Federal do Rio Grande do Sul.

2 Doutor e Mestre em Educação pela Universidade Federal de Pelotas. 
approach and dialogue between the academic knowledge and the knowledge built in the daily teaching of the school, engendering and strengthening processes of autonomy and democratic living.

Keywords: Continuing education. School democracy. Primary education.

Resumen: El artículo tiene como propósito presentar y discutir um proyecto de formación continua de profesores de la educación básica que ocurre em la ciudad de Pelotas, RS, desde 2001 llamado Encuentros sobre el Poder Escolar. Tomamos como referencia nuestra experiencia de participación en diferentes etapas de la organización y del desarrollo del proyecto y una entrevista con la primera coordinadora. Entendemos que dar visibilidad a esta acción de formación potencia la idea de acercamiento y diálogo entre los saberes académicos y los saberes construídos en los cotidianos de la docência en la escuela, engendrando y fortaleciendo procesos de autonomía y vivencia democrática.

Palabras clave: Formación continua. Democracia escolar. Educación básica.

\section{INTRODUÇÃO}

Iniciamos inspirados por Freire e Shor (1997, p. 12), quando estes asseguram que "[...] a formação científica das professoras iluminada por sua clareza política, sua capacidade, seu gosto de saber mais, sua curiosidade sempre desperta são dos melhores instrumentos políticos na defesa de seus interesses e de seus direitos." A afirmação do autor reivindica a premência de um projeto substantivo de formação e de uma práxis política, por parte das educadoras, que se contrapõe às propostas de formação continuada de docentes no molde de pacotes, uma vez que estas têm como discurso a autonomia pessoal e profissional e como intenção, professores bdela destituídos. Há nesse cenário, portanto, uma contradição entre a narrativa desses planos, que sugere uma formação crítica, e seu verdadeiro fito: docentes apassivados, domesticados, submissos e impedidos de criar.

No sentido inverso aos programas em formato de pacotes, encontra-se e sustenta-se o Projeto de formação continuada de docentes do qual trataremos 
aqui. Uma proposta que objetiva potencializar espaços de discussões coletivas, dar visibilidade às necessidades e dinâmicas locais, promover reflexões sobre o trabalho pedagógico e possibilitar suporte teórico-prático para ações escolares cotidianas ancoradas na autonomia profissional.

Tratamos o Projeto Encontros sobre o Poder Escolar, no presente texto, como uma ação de formação continuada, pois é a denominação mais utilizada e reconhecida nas escolas. Entretanto, entendemos que sua organização se sustenta na perspectiva da formação permanente (FREIRE, 1996, 2001), a qual tem como fundamento a inconclusão e o inacabamento dos sujeitos e a condição histórico-social da educação. A formação permanente proposta por Freire não privilegia a teoria ou o fazer da prática, mas busca transcender as relações hierarquizadas que inviabilizam o diálogo, valorizar a coletividade e estimular a participação de todos nos processos constantes de formação.

Metodologicamente, organizamos a discussão apresentando, inicialmente, aspectos do desenrolar do Projeto do ponto de vista de sua história, a partir de registros escritos (DALL'IGNA, 2012; CARLOS; DALL'IGNA, 2014) e de nossa experiência de participação em diferentes etapas de sua organização e desenvolvimento. Posteriormente, tomamos como referência uma entrevista narrativa (JOVCHELOVITCH; BAUER, 2002) com a primeira coordenadora que, ao contextualizar as motivações que deram origem e base ao processo, possibilitou o caminho que sustenta a investigação objeto deste texto. Por fim, trazemos alguns elementos do campo da formação de professores e dos saberes docentes, uma vez que estes foram indicados na estrutura da narração da entrevistada. Os achados da investigação nos ajudam não somente a compreender o Projeto de formação continuada Encontros sobre o Poder Escolar, mas a sustentar sua continuidade. 


\section{A HISTÓRIA DE UM PROJETO DE FORMAÇÃO CONTINUADA: OS ENCONTROS SOBRE O PODER ESCOLAR}

A formação continuada de professores integra o campo profissional daqueles que atuam na educação. Se na hodiernidade a possibilidade de participação de docentes em cursos, eventos e seminários aumentou consideravelmente em decorrência das políticas públicas de formação voltadas a esse grupo, na década de 1990 e início dos anos 2000 o cenário era diferente. $\bigcirc$ acesso a espaços de formação e de discussão sobre temáticas advindas do mundo da educação se restringia a cursos de graduação e de pós-graduação, que, notadamente, eram em quantidade bem inferiores aos existentes hoje. Em uma conjuntura social de redemocratização do País pós-Ditadura Militar, na emergência das discussões sobre a nova Lei de Diretrizes e Bases da Educação Nacional (LDB), n. 9.394/96, e no profícuo debate acerca da gestão democrática da educação surge o Projeto Encontros sobre o Poder Escolar.

Um primeiro aspecto a ser destacado na estrutura dessa proposta é o seu caráter interinstitucional. No ano 2000, sete instituições ${ }^{3}$ começam a dialogar e organizar aquele que viria a ser um dos mais importantes eventos da região Sul do Rio Grande do Sul. A escolha do seu nome, que traz consigo a ideia-força do empoderamento da escola e de seus agentes, ${ }^{4}$ foi inspirada em um trecho constante na contracapa da obra Quem manda na educação no Brasil?, de Monlevade e Silva (2000), no qual asseveram que "a democratização da sociedade e da escola exigem outro enfoque, o da construção dos processos decisórios que lentamente estão constituindo um novo poder, o poder escolar." Já a opção pela palavra encontro, a contrapelo de outras nomenclaturas

\footnotetext{
3 Participam da comissão organizadora as seguintes instituições: Faculdade de Educação/ Universidade Federal de Pelotas, Universidade Católica de Pelotas, Instituto Federal Sul-riograndense, Secretaria Municipal de Educação e Desporto de Pelotas, RS, Conselho Municipal de Educação de Pelotas, $5^{a}$ Coordenadoria Regional de Educação e $24^{\circ}$ Núcleo do CPERS-Sindicato. 4 A partir dos estudos de Freire e Shor (1997), partilhamos da ideia de empoderamento como a ação de protagonismo de mulheres e homens nas suas mais diversas ações no/com o mundo. $\bigcirc$ empoderamento é um processo de reconhecimento e reivindicação de um poder muitas vezes não compreendido ou assumido. Nesse caminhar (como sujeitos e não objetos nas relações culturais, políticas e de trabalho), ocorre a ativação das potencialidades crítica e criativa de homens e mulheres, momento que faz emergir a possibilidade de construção de práxis realmente transformadoras.
} 
(seminário, congresso...), originou-se das discussões realizadas pela comissão organizadora e do entendimento de que essa caracterização provocaria a edificação de um espaço-tempo no qual os trabalhadores em educação pudessem se encontrar, compartilhar experiências, aprender e ensinar em diálogo com os pares (DALL'IGNA, 2012, p. 55). Na conjugação entre os termos encontro e poder escolar fica evidente a base que sustenta esse Projeto de formação continuada de docentes: a compreensão de que, em diálogo com o outro, os profissionais da educação podem consubstanciar a luta por uma educação de qualidade mediante a assunção do poder que se encontra na escola e em suas possibilidades formativas. Assumir e fortalecer esse poder da escola tem sido a tarefa empreendida ao longo desses 17 anos de tão problematizadores encontros. Quanto aos objetivos específicos que estruturam a proposta, os Encontros sobre o Poder Escolar têm a intencionalidade de:

[...] contribuir para a valorização dos profissionais da educação ao dar vez e voz aos seus saberes e fazeres; trazer à luz as potencialidades criativas dos professores que, no dia a dia, compõem os cenários escolares em meio às dificuldades que permeiam a prática docente; reunir universidade e escolas de educação básica aproximando o saber acadêmico e os saberes da experiência num movimento em direção à qualificação da educação básica e do ensino universitário. (DALL'IGNA, 2012, p. 55).

Os elementos apresentados evidenciam que a proposta de formação parte da concepção de que os trabalhadores em educação necessitam ser protagonistas de sua formação e que, no cotidiano de suas escolas e diante dos processos de precarização do trabalho docente, produzem práxis educativas por meio da crítica e da criatividade pedagógica, projetando ações concretas que integram uma proposta política de qualificação dos atos de ensinar e aprender que, por seu turno, precisam ser socializadas. Cabe sublinhar, no registro que pertine aos objetivos, o diálogo entre universidade e escola, potencializando a conversa responsável e rigorosa entre os saberes acadêmicos e os da experiência.

Alicerçado nesses pilares, que se mantêm ao longo dos anos, a primeira edição do Encontro sobre o Poder Escolar acontece em 2001. Com o tema 
A escola também é poder: escolhe, rompe, decide e estimula (MONLEVADE; SILVA, 2000), discute-se acerca da escola e de seu poder. No segundo ano (2002) novamente as suas discussões são centradas no protagonismo da escola e apresenta-se como frase-título A escola como possibilidade de ousadia, rompimento, coragem e reinvenção (de autoria da jornalista e poetisa Célia Maria Maciel). Na terceira (2003), quarta (2004), quinta (2005) e sexta (2006) edições, o foco está na sala de aula e na docência como espaços de inéditos-viáveis, ${ }^{5}$ análise crítica, compromisso e recriação. ${ }^{6}$ Em sua sétima edição (2007), com a frase-tema Nossa maneira de ser na nossa maneira de ensinar (NÓVOA, 2004, p. 39), o escopo é o exercício da professoralidade e o movimento dialético que constitui o ser e o ensinar. No ano 2008 (oitava edição), o olhar do encontro é para os estudantes e o seu papel protagonista na educação, e a frase-tema é extraída da canção Coração de Estudante (de Milton Nascimento e Wagner Tiso): Há que se cuidar do broto para que a vida nos dê flor e fruto. Em 2009 (nona edição) e com a provocação Não me corte em fatias, ninguém consegue abraçar um pedaço (de Mário Quintana), o Poder Escolar mira "as complexas relações entre o uno e o múltiplo pondo em evidência a idéia da tecitura do todo através das múltiplas facetas e atividades da docência." (DALL'IGNA, 2012, p. 61). Na décima edição (2010), o momento é de festejar a trajetória de 10 anos de encontros, e a frase-tema explicita essa comemoração: Vai valer a pena ter amanhecido. ${ }^{7}$ Até a $10^{a}$ edição, os Encontros sobre o Poder Escolar eram realizados anualmente. Por compreender que se houvesse um período maior entre as edições os profissionais da educação teriam a possibilidade de aprofundar as suas experiências pedagógicas para, posteriormente, as apresentarem, o Encontro passou a ser bianual. Assim, a $11^{\text {a }}$ edição, que ocorre em 2012 e tem como slogan Por entre saberes e poderes,

\footnotetext{
5 O inédito-viável, em uma perspectiva freiriana, refere-se às possibilidades de ação de mulheres e homens mediante a tomada de consciência crítica das situações-limite que se apresentam. Em face desse movimento, surge o compromisso com a edificação de atos-limite. Dadas as condições sociais e históricas, portanto, o inédito-viável compreende a capacidade de agir concretamente sem perder o horizonte de transformação da sociedade em sua radicalidade. Ele é também um movimento de reflexão da relação dialética entre denúncia-anúncio.

6 As frases-tema foram: $3^{a}$ Edição - Sala de aula. Onde o nada acontece tudo; $4^{a}$ Edição - Repetir para acertar é ação de nossa vida diária; $5^{a}$ Edição - Na sala de aula o que fazer é não medir horizontes; $6^{a}$ Edição - A escola inquieta arrisca voos e inventa. Essas frases tiveram inspiração nos escritos de Célia Maria Maciel (DALL'IGNA, 2012).

7 Verso da música Começar de Novo (composição de Ivan Lins e Vitor Martins).
} 
a escola exercita sua autonomia, busca novamente provocar os participantes a assumirem o protagonismo de suas ações na escola. A $12^{a}$ edição, inspirada na declaração proferida pelo Prof. Mário Sérgio Cortella no $10^{\circ}$ Encontro, Na escola nem tudo pode ser feito, mas, o que pode ser feito, faremos. Temos um PODER que precisa ser exercido, aposta fortemente no exercício do poder escolar e de suas práxis possíveis. Já a 13ª edição (2017), ${ }^{8}$ diante da conjuntura histórico-social do Rio Grande do Sul e do Brasil, bem como da realidade das escolas públicas e de seus processos constituintes, elege como tema a democracia, e a frase-símbolo é de Leonardo Boff: $\bigcirc$ que concerne a todos deve ser decidido por todos.

Conjunto das frases-tema do Encontro avulta o caráter políticosocial-educativo acolhido pelo Poder Escolar: a escola tem um poder e precisa assumi-lo; os professores, ao reconhecerem que o seu trabalho é político, produzem práxis transformadoras e comprometidas socialmente com a luta pela qualidade da educação básica e os atos de ensino e aprendizagem; os docentes, ao partilharem as suas experiências, reconstroem processos de trabalho e de formação, fortalecem coletivos e ressignificam saberes.

Outro dado que deve ser observado atentamente, em se tratando do Poder Escolar, é o número de participantes e de experiências apresentadas. ${ }^{9}$ Nas edições de 2001 e 2002 havia um convite a autores de experiências pedagógicas para socializarem as suas práticas no Encontro. A partir da $3^{a}$ edição, as inscrições para a apresentação de trabalhos passou a ser aberta a todos, o que revela o compromisso, no histórico do Projeto, com a constituição de uma cultura de protagonismo por parte dos profissionais em compartilhar as suas práxis educativas. Já na $4^{a}$ edição, os resumos dos trabalhos inscritos passam a compor os anais do Encontro, e, na $5^{a}$ edição, os textos das conferências e palestras também começam a integrar esse material. Na tabela a seguir, é possível visualizar os números do Encontro sobre o Poder Escolar:

\footnotetext{
8 O intervalo de três anos entre a $12^{\mathrm{a}}$ e a $13^{\mathrm{a}}$ edição foi em virtude do entendimento, pela comissão organizadora e pelas instituições que promovem o evento, que o ano 2016 não apresentava condições favoráveis à realização do Encontro.

9 As experiências apresentadas pelos profissionais de educação versam sobre projetos/práticas pedagógicas desenvolvidas na educação infantil, nos anos iniciais e finais do ensino fundamental, no ensino médio, na Educação de Jovens e Adultos (EJA) e na gestão escolar.
} 
Tabela 1 - Número de participantes e de experiências apresentadas do $1^{\circ}$ ao $13^{\circ}$ Encontro sobre o Poder Escolar

\begin{tabular}{|c|c|c|c|c|c|c|c|c|c|c|c|c|c|}
\hline Encontro & $1^{\circ}$ & $2^{\circ}$ & $3^{\circ}$ & $4^{\circ}$ & $5^{\circ}$ & $6^{\circ}$ & $7^{\circ}$ & $8^{\circ}$ & $9^{\circ}$ & $10^{\circ}$ & $11^{\circ}$ & $12^{\circ}$ & $13^{\circ}$ \\
\hline Ano & 2001 & 2002 & 2003 & 2004 & 2005 & 2006 & 2007 & 2008 & 2009 & 2010 & 2012 & 2014 & 2017 \\
\hline $\begin{array}{l}\text { Participan- } \\
\text { tes } \\
\text { Experiên- }\end{array}$ & 1200 & 1400 & 1300 & 1800 & 1541 & 1458 & 1700 & 1646 & 1652 & 1545 & 1512 & 800 & 700 \\
\hline $\begin{array}{l}\text { cias apre- } \\
\text { sentadas }\end{array}$ & 28 & 35 & 85 & 110 & 112 & 138 & 144 & 159 & 155 & 150 & 167 & 174 & 105 \\
\hline
\end{tabular}

Um apontamento a ser destacado é que, nos últimos anos, há um crescente número de eventos relacionados à formação continuada dos profissionais da educação, muitos deles organizados pelas próprias secretarias municipais de educação. A expansão da educação a distância, por sua vez, aumentou as possibilidades formativas dos docentes. Diante do quadro exposto e resultante dele, notamos que, nas duas últimas edições (2014 e 2017), ocorreu uma diminuição no número de inscrições.

No que tange à estrutura do encontro, vale ressaltar a sua dinâmica e a capacidade de reinvenção no transcorrer dos anos. Além das conferências, palestras e mesas de apresentação de experiências, marcas do evento, outros espaços de discussão e formação foram sendo realizados entre as edições e passaram a integrar a estrutura do Projeto, como Voz dos Estudantes, Voz dos Pais, Voz das Equipes Diretivas (posteriormente renomeado como Voz dos Profissionais da Educação), Vozes da Comunidade Escolar, o curso Redes de Poder (2008-2010), as Mostras Culturais, as Rodas de Conversa e as Atividades Preparatórias (palestras e os chamados Encontrinhos). A diversidade das ações do Projeto evidencia, também, o seu compromisso com o diálogo, a constituição de coletivos e espaços de análise crítica sobre temáticas que integram o campo formativo e de trabalho.

\footnotetext{
10 A tabela de Carlos e Dall'Igna (2014) foi atualizada com informações das duas últimas edições do Encontro (2014 e 2017).
} 
A história dos Encontros sobre o Poder Escolar e a compreensão de seus princípios nos permite afirmar que esse Projeto produz significados, os quais têm nos desafiado a desenvolver estudos sobre as suas potencialidades formativas. Nesse sentido, passamos a problematizar essa questão, de maneira mais acurada, a partir das informações obtidas em uma entrevista com a Profa. Maria Antonieta Dall'Igna, primeira coordenadora da proposta.

\section{BUSCANDO SIGNIFICADOS: O QUE OS ENCONTROS SOBRE O PODER ESCOLAR TÊM A NOS DIZER?}

Caminho metodológico da investigação teve como eixo a entrevista narrativa (JOVCHELOVITCH; BAUER, 2002), na perspectiva de reconstruir um processo do ponto de vista do sujeito e considerando sua própria estrutura de narração. A professora entrevistada, ${ }^{11}$ uma das idealizadoras e primeira coordenadora do Projeto, pontuou o contexto sociopolítico e educacional que mobilizou a criação da proposta de formação continuada, bem como sua configuração e os princípios que a sustentam até os dias atuais. $\bigcirc$ arranjo narrativo dado pela entrevistada conduziu as ênfases do texto, cotejadas com os anais do evento e com um documento construído pela equipe organizadora dos Encontros sobre o Poder Escolar e direcionado para as escolas.

Conforme informações contidas na entrevista, o seu formato e propósito começou a ser delineado no ano 2000, sob influência das conquistas da Constituição Federal de 1988, das discussões sobre a Lei de Diretrizes e Bases da Educação Nacional aprovada em 1996 e dos projetos de uma escola democrática em debate no período de redemocratização do País posterior à Ditadura Militar. Ele já estava sendo gestado na década de 1990, influenciado,

\footnotetext{
11 Maria Antonieta Dall'Igna foi professora na rede estadual de ensino do RS e na Faculdade de Educação da Universidade Federal de Pelotas. Tem uma trajetória de luta, de trabalho e de pesquisas no campo das políticas educacionais, da formação de professores e da democratização da gestão da educação. Em sua investigação de doutoramento, a tese defendida foi "que os Encontros sobre o Poder Escolar possibilitam o desenvolvimento do conceito freiriano de formação permanente através da reflexão crítica, do diálogo e do trabalho coletivo, levando a mudanças pessoais e profissionais." (DALL'IGNA, 2012, p. 20).
} 
também, conforme a memória da entrevistada, pelos seminários de reestruturação curricular promovidos pela prefeitura de Porto Alegre, RS, nas gestões do Partido dos Trabalhadores (PT) e pelo momento de revitalização do Conselho Municipal de Educação de Pelotas, RS, em um período no qual havia uma intensa discussão política e pedagógica com representantes de instituições distintas e vinculadas à educação do Município. Como expressou a professora:

[...] daí a possibilidade da interinstitucionalidade, porque todas as instituições faziam parte do Conselho Municipal de Educação, eu acho que o Conselho tinha força naquela época, força de discussão pelo menos [...], então os Encontros do Poder Escolar surgem desse contexto, um contexto que era participativo e que havia ainda uma discussão política das questões da educação, um contexto que parecia que trazia a possibilidade de mudança, ainda se lutava muito por isso e as coisas estavam quentes, ele vem no rastro da redemocratização e dessa visão da necessidade de formação dos professores para uma mudança [...] e embora a Faculdade de Educação ${ }^{12}$ aqui já tivesse essa ideia desde a sua criação, havia a necessidade da formação continuada e de possibilidade de discussão com esses professores. (informação verbal).

Ele foi pensado, desde seu início, para abranger um grande número de professores da região Sul do RS, tanto da rede de ensino estadual quanto das redes municipais. Podemos pensar que a proposta de interinstitucionalidade teve seu início ali, na medida em que a referência foi o lugar e não alguma das estruturas organizacionais e administrativas das escolas. Ele pressupunha um diálogo interinstitucional para dar sustentação ao tipo de organização. A cultura interinstitucional teve forte relação, como já indicado, com a constituição e o papel do Conselho Municipal de Educação no período em que o Projeto foi originado.

Outra força mobilizadora identificada pela entrevistada foi, na época, o crescente discurso que culpabilizava os professores e seus processos de formação por problemas encontrados nas escolas. Dentre eles o baixo rendimento dos alunos e as ineficientes metodologias de ensino. Daí a concepção de um modo de formação que fosse de valorização dos professores

12 Faculdade de Educação da Universidade Federal de Pelotas (UFPel). 
e do trabalho que acontecia no interior das escolas. Ele foi se materializando na proposta de conferências com intelectuais da área e de mesas de apresentação e troca de experiências dos profissionais da educação. No início foi na forma de convites aos que tinham práticas reconhecidas, pela comissão organizadora, como promotoras de aprendizagens e desenvolvidas na perspectiva de uma escola democrática. A partir da terceira edição foram abertas inscrições para que as experiências de trabalho pudessem ser socializadas e discutidas no evento. Os critérios estabelecidos eram de que fossem trabalhos da escola e para a escola e não trabalhos acadêmicos sobre a escola. Formato bastante original na época. Muitos palestrantes vinham de outros estados ou países e faziam referência ao caráter inovador do evento, no que tangia à socialização e discussão de práticas escolares entre professores da educação básica.

Mais um fator indicado na entrevista como estimulador do Projeto foi o momento, que antecedeu o início do evento, de intensa discussão sobre eleição de diretores de escolas, construção de projetos político-pedagógicos e criação de conselhos escolares.

A questão da gestão democrática era muito quente nesse momento e teve muita influência das propostas e das bandeiras do CPERS [...]. Nesse período dos anos 80 [do século XX], a bandeira da gestão democrática, da eleição de diretores e de criação de conselhos escolares foi muito discutida [...]. Além disso, aqui em Pelotas, já no início dos anos 80, quando o Bernardo de Souza ganhou as eleições municipais, a Faculdade de Educação [UFPel] praticamente estava na base do planejamento do projeto educacional, que trabalhou em torno do fundamento freiriano. Uma das primeiras atitudes do governo foi definir que os diretores seriam eleitos, ainda não tinha entrado a questão do conselho escolar, mas da eleição dos diretores sim. Na rede estadual tinha acontecido, porque houve um período em que as escolas estaduais fizeram a eleição de diretores sem lei, já escolhiam alguns de seus diretores e nós discutíamos muito isso no núcleo do CPERS. Nós tínhamos discussões com os diretores de escola, tanto que, quando o município começou a eleger os diretores, nós, do CPERS, fomos participar junto. (informação verbal).

Discussões encharcadas do pensamento freiriano que tinham suporte na formação inicial desenvolvida pela Faculdade de Educação da UFPel e 
presentes nas propostas e discussões político-pedagógicas encaminhadas pelo CPERS/Sindicato ${ }^{13}$ no estado e na região, contexto no qual o nome do evento foi definido. A entrevista revela:

[...] a ideia da importância do projeto da escola, da gestão democrática e do trabalho coletivo se reflete no nome do encontro. Nós discutimos muito sobre qual seria o nome, por que seria esse nome [...]. Fomos vendo alguns livros, tinha o livro da Maria Abádia da Silva e do João Monlevade ${ }^{14}$ que eu já conhecia porque ele era militante da Confederação dos Professores do Brasil na época e, no sindicato, nós conhecíamos o João [...], tanto que ele veio nos dois primeiros encontros. A questão da gestão democrática era muito forte neste momento. (informação verbal).

Entendemos que o nome carrega a força dos desejos e envolvimento dos professores por uma sociedade pautada em processos decisórios coletivos, na qual a escola não está a serviço de projetos políticos que não dialogam com a comunidade escolar. Pressupõe a existência de um empoderamento que é forjado no interior da profissão e que se expressa na produção de saberes, na invenção de estratégias de luta e de caminhos de aprendizagem.

Outro aspecto abordado na entrevista foi a expectativa de contribuição do Projeto para o desenvolvimento de um trabalho coletivo nas escolas, fomentando a gestão democrática. No decorrer do processo foi possível identificar que as experiências apresentadas e discutidas pelos docentes eram, na sua maioria, referentes a processos de sala de aula que representavam iniciativas individuais ou de um pequeno grupo de professores, desvinculadas de um projeto político-pedagógico mais amplo daquela escola. Por outro lado, segundo observação da entrevistada, foi se formando um grupo de sujeitos que sistematicamente socializava suas práticas nos eventos. Esse contexto levou a comissão organizadora a propor estratégias que ampliavam o formato inicial da ação de formação.

13 Centro dos Professores do Estado do Rio Grande do Sul.

14 MONLEVADE, J.; SILVA, M. A. da. Quem manda na educação no Brasil? Brasília, DF: Idea Editora, 2000. 
[...] nós começamos a pensar que tinha que trazer a escola para falar no Poder Escolar. Nós pensamos isso foi em 2007, que para contribuir com uma discussão maior sobre as práticas escolares, nós tínhamos que nos aproximar dos professores e foi aí que surgiu a questão das Redes de Poder. (informação verbal).

A proposta das Redes de Poder era constituir um fórum de discussão permanente entre professores da educação básica e professores do ensino superior sobre as experiências apresentadas para fortalecê-las e desdobrálas, sempre na busca de mais autonomia profissional, democracia escolar e produção de saberes no contexto da escola e de seu projeto políticopedagógico. $\bigcirc$ processo também foi estimulado e desafiado, conforme revela a entrevistada, por discussões sobre gestão escolar que ocorriam no interior do Curso de Especialização em Educação promovido pela Faculdade de Educação da UFPel na primeira metade da década iniciada no ano 2000.

A proposta não chegou a se firmar. Em que pese o reconhecimento de sua importância pelos integrantes da comissão organizadora e pelos apresentadores de experiências nos encontros, as lógicas de trabalho institucional e a intensificação do trabalho docente, expressa na ausência de tempo para a interação entre os pares e para a organização e a realização de planejamentos coletivos nos diferentes níveis de ensino, possibilitaram o seu acontecimento somente entre os anos 2007 e 2008.

Seguindo na ideia de aprofundar as discussões e reconhecendo que a proposta de agregar as Redes de Poder aos Encontros sobre o Poder Escolar não alcançou os resultados esperados, foi pensada a possibilidade de provocar uma situação política e pedagógica na qual diferentes segmentos da comunidade escolar pudessem se manifestar. Destarte, foram realizadas as Vozes da Comunidade Escolar entre os anos 2008 e 2014. Encontros iniciados nas escolas, discutidos em encontros menores e socializados em edições dos Encontros sobre o Poder Escolar (ver Carlos e Dall'Igna (2014)). Da mesma forma como ocorrido com a proposta de Redes de Poder, o projeto Vozes da Comunidade Escolar não se aproximou de algo mais orgânico e amplo na relação entre escolas e entre os segmentos que compõem a comunidade escolar como pais, professores, alunos e equipe diretiva. Mesmo assim, 
ocorreram agregando grupos vinculados a um número pequeno de escolas, em torno de 10, provocando discussões sobre temáticas definidas no próprio processo e possibilitando experiências de encontro informadas pelas relações que ocorrem no interior das escolas e vivenciadas nos cotidianos escolares. Queremos destacar a persistência dentro do Projeto de iniciativas pautadas por anseios democráticos e de busca por brechas no instituído que indicam possibilidades de autonomia profissional. São processos constantemente reavaliados, os quais encaminham as próximas ações ao longo dos últimos 17 anos. Um tempo que não é curto se tomarmos como referência a cultura de gestões públicas embaladas por políticas de governo marcadas pela ausência de participação dos docentes e demais profissionais da educação, bem como da comunidade escolar, nas tomadas de decisões.

Desse modo persistente, em 2015 foi iniciado um processo denominado pela comissão organizadora de ações preparatórias para o $13^{\circ}$ Encontro sobre o Poder Escolar. Foram enviadas correspondências eletrônicas para as escolas públicas da região com o chamamento para reuniões, que tinham como foco a gestão escolar. Destacamos o trecho de uma correspondência de setembro de 2015:

Encontros sobre o Poder Escolar é um projeto que tem como prática repensar-se continuamente, mantendo como referência um panorama social mais amplo. Desta forma, a comissão organizadora, ao avaliar e refletir sobre a política educacional atual e os processos de formação encaminhados até aqui, entende que estamos em um momento de recuo da gestão democrática das escolas, sendo necessário retomar e fortalecer este debate nas ações do projeto. Como fazer? Apostamos que dar visibilidade e buscar compreender como algumas escolas ainda conseguem dar vazão e manter ações pautadas na autonomia e na democracia de projetos pedagógicos é uma estratégia formativa que poderá auxiliar os processos nas demais, bem como qualificar os que estão em andamento. Assim, saudamos as escolas que atenderam à nossa provocação expressa na carta [...] e convidamos para uma reunião [...]. Reafirmamos a nossa solidariedade com essas iniciativas e a intenção de que o $13^{\circ}$ Encontro sobre o Poder Escolar possa contribuir e ampliar o que está sendo realizado nas escolas da região. (informação verbal). 
conteúdo do texto expresso anteriormente mostra que o evento se constrói na perspectiva do diálogo com as escolas. Mesmo que as expectativas da comissão organizadora não sejam atingidas, há um processo sempre em ação que vai tecendo vínculos, fomentando encontros, forjando espaços de formação com autonomia em relação às próprias instituições parceiras. Foi se institucionalizando algo acima do instituído, mesmo que algumas das entidades parceiras sejam responsáveis por encaminhar políticas de governo distanciadas dos propósitos do Projeto.

Professores membros da equipe diretiva de 16 escolas constituíram um grupo de trabalho no ano 2015. Os encontros do grupo ocorreram com uma periodicidade mensal até meados de 2016 e, posteriormente, converteram-se em reuniões organizativas do $13^{\circ}$ Encontro sobre o Poder Escolar, que ocorreu em julho do ano 2017. Os encontros foram sintomáticos da sobrecarga de trabalho dos gestores e das exigências burocráticas que conflitavam com encaminhamentos locais, da insuficiência de professores para o bom atendimento das demandas da escola, da precariedade da estrutura física e de outros tantos pontos indicadores de negligências com a educação pública. Ainda que muitas mazelas já sejam conhecidas, os pronunciamentos socializados nas reuniões, muitos como desabafos, mostraram ausência de projetos pedagógicos referenciados localmente e dificuldades de estabelecer tomadas de decisão mais coletivas. Nas falas, o que se apresentou como algo comum foi uma identificação de que o estreitamento de vínculos entre escola e comunidade seria a ação mais potente a ser realizada.

Nesse processo identificamos as consequências de uma cultura de responsabilização individual pela administração das escolas. Entendemos que teve suas bases nas políticas de descentralização de financiamento e custeio da educação pública, as quais delegaram poderes para as escolas na década de 1990 pautadas em pressupostos do individualismo na organização social (POPKEWITZ, 1997). A transferência de responsabilidade de uma estrutura centralizada para um contexto local carrega um entendimento da escola como instituição prestadora de serviço que visa à eficiência e não como local de vivência social e de formação. Parece-nos que o desejo por descobrir modos de aproximação com a comunidade escolar seria uma brecha, uma tentativa de autonomia. 
Sintonizados com o processo, organizamos o evento do ano 2017 tendo como eixo articulador a democracia nas conferências e rodas de conversa. As avaliações das ações mais recentes estão em curso, e o Projeto segue sua dinâmica.

\title{
4 DIALOGANDO COM OS ESTUDOS SOBRE FORMAÇÃO E TRABALHO DE PROFESSORES
}

Ao observar a estrutura de narração da professora entrevistada identificamos elementos vinculados ao contexto da formação e do trabalho docente, os quais foram os disparadores de uma característica singular do Evento: as mesas de apresentações de experiências escolares. Nelas, os profissionais da educação socializam saberes da prática pedagógica, trocam experiências com os pares e produzem reflexões sobre os quefazeres do cotidiano escolar. Desse modo, abre-se a possibilidade de compreender as dinâmicas do ato educativo em uma perspectiva mais alargada, evitando assumir para si a culpa dos fracassos vinculados à educação. Conforme a entrevistada:

\begin{abstract}
Tinha outra questão, que era a culpabilização dos professores pelos problemas da educação [...] então veio a necessidade de valorização dos professores. E a valorização qual era? Por onde? Uma pela formação, por novas teorias, explicações de pessoas conhecidas no mundo da educação e a outra para mostrar o que os professores estavam fazendo através do seu próprio trabalho, aí então a ideia das mesas de apresentações de experiências. (informação verbal).
\end{abstract}

Cabe observar, a partir da fala da entrevistada, que as palestras proferidas no evento se configuraram uma possibilidade profícua de diálogo com as produções da área da formação de professores, oportunizando a ressignificação de suas práticas. Para os palestrantes, é um momento provocativo de tensionamento sobre o que produzem teoricamente. No entrecruzamento dessas ações/relações, saberes são reconstruídos. 
Olhando para a história dessa ação - a qual já está integrada na cultura de formação continuada dos professores de Pelotas, RS, e região observamos, por meio dos elementos apresentados na entrevista, indicadores que nos ajudam a compreendê-la em estudos do campo da formação de professores e dos saberes docentes. Parece-nos que algumas investigações acadêmicas engendram o processo e são constituídas também por elementos nele presentes.

Articuladas ao exposto, destacamos as discussões sobre os saberes docentes que passam a integrar os debates da comunidade educacional nos anos 1990 (TARDIFF; LESSARD; LAHAYE, 1991; GAUTHIER et al., 1998); os debates em torno da ideia de professor reflexivo e professor pesquisador, vinculados a um movimento de valorização da formação e da profissionalização dos professores também a partir dos anos 1990 no Brasil (PIMENTA, 2005), e estudos que estabelecem críticas às propostas dirigidas individualmente aos professores (NÓVOA, 1991; GATTI, 2008; FREITAS, 2012; CUNHA, 2014) e, portanto, desvinculadas de um projeto profissional coletivo e da carreira docente. Ao mesmo tempo que pesquisas impulsionaram e sustentam as estratégias de formação dos Encontros sobre o Poder Escolar, ele e outras ações, que também se pautam na compreensão de que propostas direcionadas individualmente aos professores não estimulam a construção de saberes no interior da profissão, ampliam e fortalecem as discussões no campo teórico. Foram estudos que fizeram uso de uma abordagem teórica e metodológica que aproximava o pessoal do profissional, que considerava os cotidianos do trabalho docente, bem como os saberes profissionais fundados nesses contextos. $\bigcirc$ entendimento era de que o professor está implicado na sua formação, em um processo em que os saberes da formação inicial são constantemente reelaborados e em que a reflexão na e sobre a prática vai gestando novos saberes.

Desse modo, o Projeto foi se configurando na esteira de uma compreensão que estava se constituindo, a de que o trabalho docente, com seus saberes e sua prática, demanda uma formação que não se limita ao acadêmico, mas se alarga, implicada nas múltiplas dimensões da função, no espaço e no tempo no qual se exerce a profissão. As conferências permitiam questionar e reelaborar os saberes de referência dos professores, e as mesas 
de apresentação de experiência possibilitavam trocas entre os pares sobre os saberes e os fazeres da prática docente escolar, dando visibilidade para o cotidiano da prática profissional. Os professores estavam sendo considerados como profissionais, no sentido atribuído por Gauthier (1998), quando trata das bases que vão sustentando a pedagogia a partir da década de 1980. Para o autor, o profissional é:

[...] aquele que, munido de saberes e confrontando a uma situação complexa que resiste à simples aplicação dos saberes para resolver a situação, deve deliberar, julgar e decidir com relação à ação a ser adotada, ao gesto a ser feito ou à palavra a ser pronunciada antes, durante e após o ato pedagógico. (GAUTHIER, 1998, p. 331).

Nesse contexto, Tardif (2002, p. 196) afirma que os saberes docentes se constituem quando, além de saber fazer, o docente sabe fundamentar o que faz, ou seja, não simplesmente emite "um juízo verdadeiro a respeito de algo [...] [mas também é] capaz de determinar por que razões esse juízo é verdadeiro." Entendemos que as dinâmicas dos Encontros sobre o Poder Escolar, com preponderância para as mesas de apresentação e discussão de práticas escolares, potencializam que experiências profissionais mais circunscritas ao âmbito pessoal ganhem amplitude e se tornem um saber manifesto, fundamentado pelo profissional protagonista da ação. Mesmo que prevaleçam socializações de modos de fazer cotidianos, marcados pela lógica de encontrar estratégias para situações imediatas e para as quais os procedimentos têm elevado valor, estes são singulares, oriundos do contexto e fazer local. Auferem um redimensionamento quando expostos àquela situação formativa.

As experiências pedagógicas apresentadas pelos docentes da educação básica e discutidas com os pares nos eventos dos Encontros sobre o Poder Escolar são campo de formação e de possibilidade de ampliação da compreensão das práticas pedagógicas. Ao lançar mão de suas experiências docentes, os professores trazem à tona seus cotidianos de trabalho, ora dialogando com questões macro, ora permanecendo em situações mais imediatas de ensino nas quais a discussão teórica, muitas vezes, se fragiliza. Contextualizá-las coletivamente perturba uma tradição cultural que 
responsabiliza individualmente o docente por suas ações e dinâmicas no mundo do trabalho. Além disso, promove a ideia de comunidades de aprendizagem nas quais o que um profissional vivencia pode cooperar com os demais.

Ainda, como princípios que distinguem o Projeto, e já expressos no texto de Carlos e Dall'Igna (2014), estão o entendimento de que as mudanças desejadas na educação escolar dependem da construção coletiva, democrática e autônoma de seus projetos (PARO, 2001); a compreensão de que os professores aprendem na troca de experiências, no encontro, no trabalho conjunto e colaborativo (FULLAN; HARGREAVES, 1999); e a convicção de que o exercício da reflexão crítica sobre a prática é uma exigência da relação entre a teoria e a prática na qual se evita o ativismo e o discurso descolado da realidade objetiva (FREIRE, 1997).

\section{CONSIDERAÇÕES FINAIS}

A análise sobre a história do Projeto Encontros sobre o Poder Escolar e os processos que o suleiam permitem a afirmação de que a proposta inovou ao conceber uma dinâmica diferenciada de formação continuada. Desde a sua gênese, o Encontro e suas ações objetivam que os trabalhadores em educação acessem um espaço formativo de diálogo, de protagonismo e de ressignificação de suas práxis. Compreender que esses profissionais, no exercício de seu trabalho, produzem saberes foi outro compromisso assumido pelo coletivo que encaminhou os primeiros passos da ação. Entendimento que ganhou substantividade no desenvolvimento do Encontro e que acabou sendo uma de suas características mais notáveis. Associadas a este, embasam a proposta como princípios: a consciência de que, no trabalho colaborativo e autônomo, as pequenas e grandes mudanças na educação começam a ser fomentadas; a percepção da necessidade de socialização das práticas pedagógicas e que esta possibilita a análise crítica do trabalho desenvolvido, qualificando-o e favorecendo a emergência de uma práxis educativa estribada na reflexão sobre a prática, que se contrapõe, no conteúdo e na forma, ao praticismo e ao ativismo retórico. 
Ainda, cabe ressaltar que o Projeto, em seu formato organizacional, intensifica uma rede solidária entre as instituições, o que favorece o diálogo e a escuta atenta ao diverso, oportunizando a reinvenção da proposta ao longo dos anos. $\bigcirc$ Encontro sobre o Poder Escolar já se constitui, em virtude de sua caracterização e de seus pilares, como uma instituição.

Por sua lógica de formação crítica e provocadora do protagonismo docente, a qual diverge de eventos de caráter motivacional em evidência na atualidade, o Poder Escolar tem contribuído para a qualificação dos processos formativos e das práxis pedagógicas realizadas nas escolas da região Sul do Estado do Rio Grande do Sul. Como registros comprobatórios dessa assertiva, destacamos: a proeminência das experiências apresentadas por profissionais da educação e que, a partir das problematizações feitas nas mesas temáticas, têm sido aprofundadas; os relatos produzidos nas avaliações dos Encontros, que asseguram a sua qualidade e sublinham o seu formato; o significativo número de professores que participam e apresentam trabalhos no Encontro, o que demonstra que o Poder Escolar está presente na cultura de formação continuada; o número de investigações, em nível de mestrado e doutorado, que começam a ser realizadas em decorrência da longevidade do Encontro, dos dados que ele produz e de seus registros nos anais do evento; o surgimento de outros seminários, na região Sul do RS, que se organizam a partir da estrutura do Poder Escolar.

necessário diálogo entre os saberes da experiência e aqueles provenientes da ação pedagógica, como provocadores de uma práxis educativa comprometida com a mudança radical, tem sido constante nos espaços dos Encontros sobre o Poder Escolar. A conjugação dessa relação potencializa a constituição de um saber ressignificado e problematizador da docência, o qual engendra leituras críticas da realidade, tensiona aspectos da formação e da profissionalização, causa rupturas com processos alienantes, reivindica o protagonismo dos trabalhadores em educação e estabelece coletivos de ação, de luta e de construção colaborativa de saberes. 


\section{REFERÊNCIAS}

CARLOS, L. C.; DALL'IGNA, M. A. Formação continuada de docentes de escola pública: empoderamento e democracia. Expressa Extensão, v. 19, n. 1, p. 71-79, jun./nov. 2014. Disponível em: <http://wp.ufpel.edu.br/poderescolar/ files/2016/07/4432-121 13-1-PB-1.pdf>. Acesso em: 20 jun. 2017.

CUNHA, M. I. da. Aprendizagem da docência em espaços institucionais: é possível fazer avançar o campo da formação de professores? Avaliação, v. 19, n. 3, p. 789-802, nov. 2014. Disponível em: <http://www.scielo.br/pdf/aval/ v19n3/13.pdf>. Acesso em: 20 jun. 2017.

DALLIGNA, M. A. Por entre encontros e saberes: a formação docente em diálogo com o "Poder Escolar" e o pensamento freiriano. 2012. 217 p. Tese (Doutorado em Educação)-Faculdade de Educação, Programa de Pós-Graduação em Educação, Universidade Federal de Pelotas, Pelotas, 2012.

FREIRE, P. Pedagogia da autonomia: saberes necessários à prática educativa. 39. ed. São Paulo: Paz e Terra, 1996.

FREIRE, P. Política e Educação. 5. ed. São Paulo: Cortez, 2001.

FREIRE, P. Professora sim, tia não: cartas a quem ousa ensinar. São Paulo: Olho d'Água, 1997.

FREIRE, P.; SHOR, I. Medo e Ousadia - O Cotidiano do Professor. Tradução Adriana Lopez. 7. ed. Rio de Janeiro: Paz e Terra, 1997.

FREITAS, H. C. L. Formação inicial e continuada: a prioridade ainda postergada. In: OLIVEIRA, D. A.; VIEIRA, L. F. (Org.). Trabalho na Educação Básica: a condição docente em sete estados brasileiros. Belo Horizonte: Fino Traço, 2012. p. 91-129.

FULLAN, M.; HARGREAVES, A. A escola como organização aprendente: buscando uma educação de qualidade. Porto Alegre: Artes Médicas Sul, 1999.

GATTI, B. A. Análise das políticas públicas para formação continuada no Brasil, na última década. Revista Brasileira de Educação, v. 13, n. 37, p. 57-70, jan./abr. 2008. Disponível em: <http://www.scielo.br/pdf/rbedu/vl3n37/06. pdf $>$. Acesso em: 20 jun. 2017.

GAUTHIER, C. et al. Por uma teoria da Pedagogia. Ijuí: Ed. Unijuí, 1998. 
JOVCHELOVITCH, S.; BAUER, M. Entrevista narrativa. In: BAUER, M.; GASKELL, G. (Org.). Pesquisa qualitativa com texto, imagem e som. Petrópolis: Vozes, 2002. p. 90-113.

MONLEVADE, J.; SILVA, M. A. da. Quem manda na educação no Brasil? Brasília, DF: Idea Editora, 2000.

NÓVOA, A. Concepções e práticas da formação contínua de professores: In: NÓVOA, A. (Org.). Formação contínua de professores: realidade e perspectivas. Portugal: Universidade de Aveiro, 1991. p. 15-38.

NÓVOA, A. Diz-me como ensinas, dir-te-ei quem és e vice-versa. In: FAZENDA, I. C. A. (Org.). A pesquisa em educação e as transformações do conhecimento. 6. ed. Campinas: Papirus, 2004. p. 29-41.

PARO, V. H. Administração escolar e qualidade do ensino: o que os pais ou responsáveis têm a ver com isso? In: PARO, V. H. (Org.). Escritos sobre educação. São Paulo: Xamã, 2001. p. 101-112.

PIMENTA, S. G. Professor reflexivo: construindo uma crítica. In: PIMENTA, S. G.; GHEDIN, E. (Org.). Professor reflexivo no Brasil: gênese e crítica de um conceito. 3. ed. São Paulo: Cortez, 2005. p. 17-52.

POPKEWITZ, T. S. Reforma Educacional: uma política sociológica. Porto Alegre: Artes Médicas, 1997.

TARDIF, M.; LESSARD, C.; LAHAYE, L. Os professores face ao saber: um esboço de uma problemática do saber docente. Teoria e Educação, Porto Alegre, v. 1, n. 4, p. 215-233, 1991.

TARDIF, M. Saberes Docentes e Formação Profissional. São Paulo: Cortez, 2002 .

Endereços para correspondência: Rua Coronel Alberto Rosa, 154, $2^{\circ}$ andar, Bairro Várzea do Porto, 960 10-770, Pelotas, Rio Grande do Sul, Brasil; li. gi.c@hotmail.com 